\title{
Improved Direct Displacement-Based Design Procedure for Performance-Based Seismic Design of Structures
}

\author{
Rakesh K. Goel, California Polytechnic State University, San Luis Obispo, \\ and Anil K. Chopra, University of California, Berkeley
}

\begin{abstract}
Direct displacement-based design requires a simplified procedure to estimate the seismic deformation of an inelastic SDF system, representing the first (elastic) mode of vibration of the structure. This step is usually accomplished by analysis of an "equivalent" linear system using elastic design spectra. In this paper, an equally simple procedure is developed that is based on the well-known concepts of inelastic design spectra. This procedure provides: (1) accurate values of displacement and ductility demands, and (2) a structural design that satisfies the design criteria for allowable plastic rotation. In contrast, the existing procedure using elastic design spectra for equivalent linear systems is shown to underestimate significantly the displacement and ductility demands. The existing procedure is shown to be deficient in yet another sense; the plastic rotation demand on structures designed by this procedure may exceed the acceptable value of the plastic rotation, leaving an erroneous impression that the allowable plastic rotation constraint has been satisfied.
\end{abstract}

\section{Introduction}

Direct displacement-based design is being advocated as a more rational and relevant approach to seismic design of structures compared to traditional strength-based design (Shibata and Sozen, 1976; Moehle, 1992; Kowalsky, Priestley, and MacRae, 1994). Displacement-based design involves several steps (to be described later), one of which is to estimate the seismic deformation of an inelastic SDF system representing the first (elastic) mode of vibration of the MDF system. In some of the present procedures, this step is accomplished by approximate methods in which the nonlinear system is replaced by an "equivalent" linear system (Shibata and Sozen, 1976; Priestley, Seible, and Calvi, 1996). The period and damping of this linear system are determined by the secant stiffness method (Jennings, 1968) or its variants, e.g., the substitute structure method (Shibata and Sozen, 1976).

The purpose of this paper is to demonstrate application of inelastic design spectra to direct displacement-based design of structures. The resulting design procedure is shown to produce a satisfactory structural design. In contrast, it is shown that the design produced by the procedure that uses elastic design spectra and equivalent linear systems does not necessarily satisfy the design criteria. In particular, it can leave an erroneous impression that the allowable plastic rotation constraint has been satisfied. Note that this paper is a summary of a recent full-length manuscript accepted for publication (Chopra and Goel, 2000). 
This presentation is intentionally restricted to structures idealized as SDF systems with bilinear force-deformation relations (Figure 1). The distraction of approximations inherent in a one-mode representation of MDF systems and bilinear idealization of a pushover curve are thus avoided.

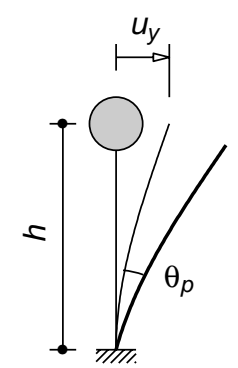

(a)

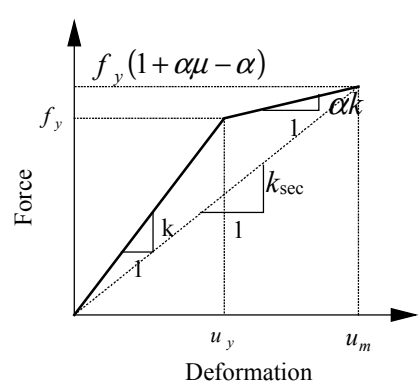

(b)

Figure 1. Idealized SDF system with bilinear force-deformation relation.

\section{Displacement-Based Design Using Elastic Design Spectra}

Equivalent Linear System. Needed in existing displacement-based design procedures, the properties of the equivalent linear system are summarized here. Consider an inelastic SDF system with bilinear force-deformation relationship on initial loading (Figure 1b). The stiffness of the elastic branch is $k$ and that of the yielding branch is $\alpha k$. The yield strength and yield displacement are denoted by $f_{y}$ and $u_{y}$, respectively. If the peak (maximum absolute) deformation of the inelastic system is $u_{m}$, the ductility factor $\mu=u_{m} / u_{y}$.

For the bilinear system of Figure 1b, the natural vibration period of the equivalent linear system with stiffness equal to $k_{\text {sec }}$, the secant stiffness, is

$$
T_{e q}=T_{n} \sqrt{\frac{\mu}{1+\alpha \mu-\alpha}}
$$

where $T_{n}$ is the natural vibration period of the system vibrating within its linearly elastic range $\left(u \leq u_{y}\right)$.

The most common method for defining equivalent viscous damping is to equate the energy dissipated in a vibration cycle of the inelastic system and of the equivalent linear system. Based on this concept, it can be shown that the equivalent viscous damping ratio is (Chopra and Goel, 1999):

$$
\zeta_{\text {eq }}=\frac{2}{\pi} \frac{(\mu-1)(1-\alpha)}{\mu(1+\alpha \mu-\alpha)}
$$

The total viscous damping of the equivalent linear system is

$$
\hat{\zeta}_{e q}=\zeta+\zeta_{e q}
$$

where $\zeta$ is the viscous damping ratio of the bilinear system vibrating within its linearly elastic range $\left(u \leq u_{y}\right)$. 


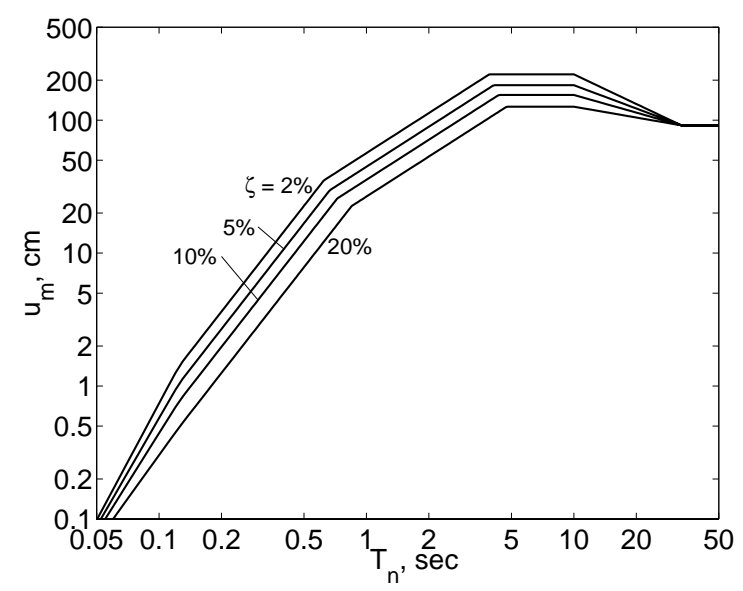

Figure 2. Elastic deformation design spectrum.

Elastic Design Spectra. To implement the existing displacement-based design procedure, an elastic design spectrum is needed. For this purpose, a median-plus-one-standard-deviation spectrum constructed for peak values of the ground acceleration, velocity, and displacements of $\ddot{u}_{g o}=1 g, \dot{u}_{g o}=122 \mathrm{~cm} / \mathrm{s}(48 \mathrm{in} / \mathrm{s})$, and $u_{g o}=91.4 \mathrm{~cm}(36 \mathrm{in})$, respectively, by the procedure of Newmark and Hall (1982) is used. The displacement (or deformation) design spectrum needed in the displacement-based design is determined from the standard pseudo-acceleration design spectrum, using the well-known relationship between pseudo-acceleration $A$ and deformation $D$ :

$$
u_{m}=D=\left(\frac{T_{n}}{2 \pi}\right)^{2} A
$$

Figure 2 shows such spectra for several values of the damping ratio.

Step-By-Step Procedure. Adapted from Priestley and Calvi (1997), a direct displacement-based design procedure for bilinear SDF systems (Figures 1a and 1b) using elastic design spectra is outlined as a sequence of steps:

1. Estimate the yield deformation $u_{y}$ for the system.

2. Determine acceptable plastic rotation $\theta_{p}$ of the hinge at the base.

3. Determine design displacement $u_{m}$

$$
u_{m}=u_{y}+h \boldsymbol{\theta}_{p}
$$

and design ductility factor $\mu=u_{m} / u_{y}$.

4. Estimate the total equivalent viscous damping, $\hat{\zeta}_{e q}$, for the design ductility factor from Equations 2 and 3.

5. Enter the deformation design spectrum for elastic systems with known $u_{m}$ and $\hat{\zeta}_{\text {eq }}$ to read $T_{e q}$ (Figure 2). Determine the secant stiffness 


$$
k_{\mathrm{sec}}=\frac{4 \pi^{2}}{T_{e q}^{2}} m
$$

where $m$ is the mass of the system.

6. Determine the required yield strength $f_{y}$ from Figure 1b:

$$
f_{y}=\frac{k_{\mathrm{sec}} u_{m}}{1+\alpha \mu-\alpha}
$$

7. Estimate member sizes and detail (reinforcement in $\mathrm{R} / \mathrm{C}$ structures, connections in steel structures) to provide $f_{y}$. Calculate initial elastic stiffness $k$ and $u_{y}=f_{y} / k$.

8. Repeat steps 3 to 7 until a satisfactory solution is obtained.

Example. Consider a portion of a long reinforced-concrete viaduct that is a part of a freeway. The total weight of the superstructure, $190 \mathrm{kN} / \mathrm{m}$, is supported on identical bents $9 \mathrm{~m}$ high, uniformly spaced at $39.6 \mathrm{~m}$. Each bent consists of a single circular column $1.5 \mathrm{~m}$ in diameter (Figure 3a). Using the design procedure described earlier, this system is designed (longitudinal reinforcement of the column) for the design earthquake defined by Figure 2 scaled to $\ddot{u}_{g o}=0.5 \mathrm{~g}$.

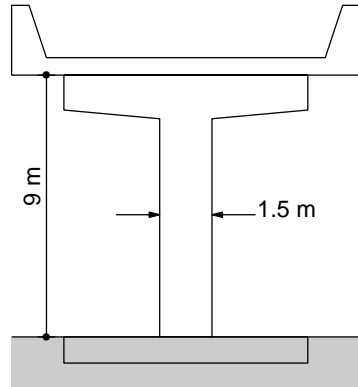

(a)

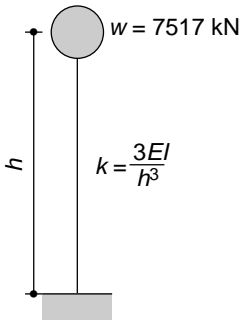

(b)

Figure 3. Example single-column bent and idealized SDF system.

For the transverse ground motion, the viaduct can be idealized as an SDF system (Figure $3 b$ ) with its lateral stiffness computed from $k=3 E I / h^{3}$, where $E$ is the elastic modulus of concrete, $I$ is the effective moment of inertia of the reinforced-concrete cross section, and $h$ is the column height. Based on the American Concrete Institute design provisions ACI 318-95, the effective EI for circular columns subjected to lateral load is given by $E I=E_{c} I_{g}\left(0.2+2 \boldsymbol{\rho}_{t} \boldsymbol{\gamma}^{2} E_{s} / E_{c}\right)$ where $I_{g}$ is the second moment of inertia of the gross section, $E_{c}$ and $E_{s}$ are the elastic moduli of concrete and reinforcing steel, $\rho_{t}$ is the longitudinal reinforcement ratio, and $\gamma$ is the ratio of the distances from the center of the column to the center of the outermost reinforcing bars and to the column edge.

The system properties selected are: concrete strength $=27.6 \mathrm{MPa}(4 \mathrm{ksi})$, steel strength $=413$ $\mathrm{MPa}(60 \mathrm{ksi})$ and $\gamma=0.9$. The mass of the idealized SDF system is the tributary mass for one bent, i.e., the mass of $39.6 \mathrm{~m}$ length of the superstructure, $m=w / g=$ $(7517 \times 1000 \mathrm{~N}) / 9.8 \mathrm{~m} / \mathrm{s}^{2}=767041 \mathrm{~kg}$. The initial elastic vibration period of this system is 1.82 $\mathrm{s}$, which falls in the velocity-sensitive region of the design spectrum. 
The step-by-step procedure described earlier in this section is now implemented as follows:

1. An initial estimate of $u_{y}=4.5 \mathrm{~cm}$.

2. The plastic rotation acceptable at the base of the column is $\theta_{p}=0.02$ radians.

3. The design displacement given by Equation 6 is $u_{m}=u_{y}+h \theta_{p}=4.5+900 \times 0.02=22.5 \mathrm{~cm}$ and the design ductility factor is $\mu=u_{m} / u_{y}=22.5 / 4.5=5$.

4. For $\alpha=5 \%$ and $\mu=5$, Equations 2 and 3 give $\hat{\zeta}_{e q}=45 \%$.

5. The deformation design spectrum for elastic systems is constructed for $\hat{\zeta}_{e q}=45 \%$. Corresponding to $u_{m}=22.5 \mathrm{~cm}$ this spectrum gives $T_{e q}=2.81 \mathrm{~s}$ and $k_{\mathrm{sec}}$ is computed by Equation $7, k_{\mathrm{sec}}=(2 \pi / 2.81)^{2} \times 767041=3.835 \times 10^{6} \mathrm{~N} / \mathrm{m}=38.35 \mathrm{kN} / \mathrm{cm}$.

6. The yield strength is given by Equation $8, f_{y}=(38.35 \times 22.5) /(1+0.05 \times 5-0.05)=719.1$ $\mathrm{kN}$.

7. The circular column is then designed using ACI318-95 for axial load due to superstructure weight of $7517 \mathrm{kN}$ plus column self weight of $375 \mathrm{kN}$ and the bending moment due to lateral force $=f_{y}: M=h f_{y}=6472 \mathrm{kN}-\mathrm{m}$. For the resulting column design, $\rho_{t}=1.19 \%$, flexural strength $=7395 \mathrm{kN}-\mathrm{m}$, and lateral strength $=821.7 \mathrm{kN}$. For $\rho_{t}=1.19 \%$, $E I=2.22 \times 10^{6} \mathrm{kN}-\mathrm{m}^{2}, k=91.3 \mathrm{kN} / \mathrm{cm}$, and $u_{y}=f_{y} / k=821.7 / 91.3=9 \mathrm{~cm}$.

8. Since the yield deformation computed in Step 7 differs significantly from the initial estimate of $u_{y}=4.5 \mathrm{~cm}$, iterations are necessary.

The procedure converged after three iterations giving a column design with $\rho_{t}=1.3 \%$. This column has an initial stiffness, $k=95.17 \mathrm{kN} / \mathrm{cm}$ and lateral yield strength, $f_{y}=839.7 \mathrm{kN}$. The deformation demand $u_{m}=26.8 \mathrm{~cm}$. Due to reason of brevity, results of intermediate iterations are not presented here; they are available in Chopra and Goel (2000).

\section{Displacement-Based Design Using Inelastic Design Spectra}

Presented next is a direct displacement-based design procedure that uses the well-known constant-ductility design spectra instead of the elastic design spectra for equivalent linear systems.

Inelastic Design Spectrum. A constant-ductility spectrum for an elastoplastic hysteretic system is a plot of $A_{y}$ versus the initial elastic period $T_{n}$ for selected values of $\mu$. The pseudoacceleration $A_{y}$ is related to the yield strength $f_{y}$ by $f_{y}=\left(A_{y} / g\right) w$ where $w$ is the weight of the system. The yield strength reduction factor is given by $R_{y}=f_{o} / f_{y}=A / A_{y}$ where $f_{o}=(A / g) w$ is the minimum yield strength required for the structure to remain elastic during the earthquake; $\mathrm{A}$ is the pseudo-acceleration ordinate of the elastic design spectrum at $\left(T_{n}, \zeta\right)$. 
A constant-ductility design spectrum is established by dividing the elastic design spectrum by appropriate ductility-dependent factors that depend on $T_{n}$; detailed procedure is described in Chopra (1995, Chapter 7). The Newmark and Hall (1982) recommendations for the reduction factor, $R_{y}$, are $\sqrt{2 \mu-1}$ in the acceleration-sensitive region, and $\mu$ in the velocity- and displacement-sensitive regions. In recent years, several other recommendations for the reduction factor have been developed (Krawinkler and Nassar, 1992; Vidic, Fajfar, and Fischinger, 1994; Miranda and Bertero, 1994).

The peak deformation $u_{m}$ of the inelastic system is given by:

$$
u_{m}=\mu\left(\frac{T_{n}}{2 \pi}\right)^{2} A_{y}=\mu \frac{1}{R_{y}}\left(\frac{T_{n}}{2 \pi}\right)^{2} A
$$

Computed by using Equation 9 and $R_{y}-\mu$ relations of Newmark and Hall (1982), the deformation design spectrum is shown in Figure 4.

Step-By-Step Procedure. The first three steps of this procedure are identical to those in the previously-described displacement-based design procedure, and steps 4 to 8 are replaced by the following steps based on the deformation design spectra for inelastic systems (Figure 4).

4. Enter Figure 4 with known $u_{m}$ and $\mu$ to read $T_{n}$. Determine the initial elastic stiffness:

$$
k=\frac{4 \pi^{2}}{T_{n}^{2}} m
$$

5. Determine the required yield strength

$$
f_{y}=k u_{y}
$$

6. Estimate member sizes and detail (reinforcement in $\mathrm{R} / \mathrm{C}$ structures, connections in steel structures, etc.) to provide the strength determined from Equation 11. For the resulting design of the structure, calculate the initial elastic stiffness $k$ and yield deformation $u_{y}=f_{y} / k$.

7. Repeat steps 3 to 6 until a satisfactory solution is obtained.

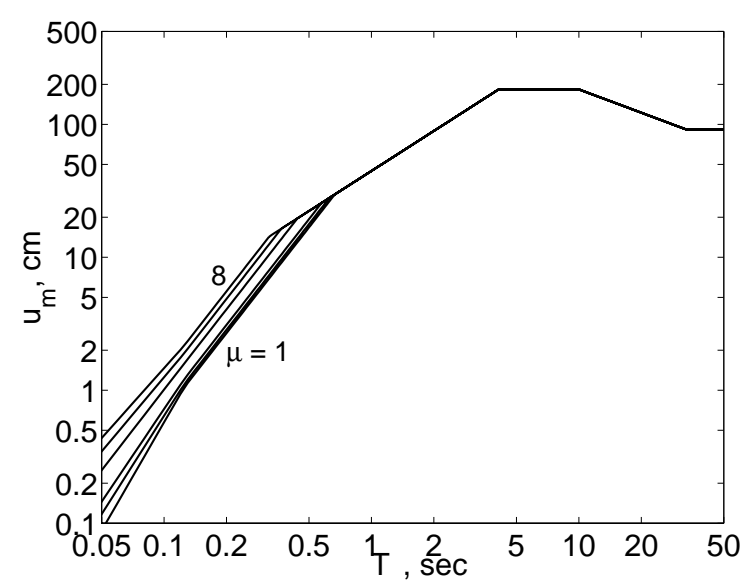

Figure 4. Inelastic deformation design spectra. 
The graphical implementation of Step 4 in the modified design procedure may be attractive for its similarity to the previous procedure. However, the graphical feature is not essential and the Step 4 can be implemented numerically; from Equation (9)

$$
T_{n}=2 \pi \sqrt{\frac{u_{m}}{A} \frac{R_{y}}{\mu}}
$$

where $R_{y}$ and $\mu$ are related, for example, by relations of Newmark and Hall (1982). Because this relation depends on $T_{n}$, iteration may be necessary to determine $T_{n}$ from Equation 12 .

Example. The step-by-step procedure described in this section is now implemented for the system designed previously by the displacement-based design procedure using the elastic design spectra.

1. An initial estimate of $u_{y}=4.5 \mathrm{~cm}$.

2. The plastic rotation acceptable at the base of the column is $\theta_{p}=0.02$ radians.

3. The design displacement given by Equation 6 is $u_{m}=u_{y}+h \theta_{p}=4.5+900 \times 0.02=22.5 \mathrm{~cm}$ and the design ductility factor is $\mu=u_{m} / u_{y}=22.5 / 4.5=5$.

4. The deformation design spectrum for inelastic systems is constructed for $\mu=5$. Corresponding to $u_{m}=22.5 \mathrm{~cm}$, this spectrum gives $T_{n}=1.01 \mathrm{~s}$ and $k$ is computed by Equation $10, k=(2 \pi / 1.01)^{2} \times 767041=29.9 \times 10^{6} \mathrm{~N} / \mathrm{m}=298.7 \mathrm{kN} / \mathrm{cm}$.

5. The yield strength is given by Equation 11, $f_{y}=k u_{y}=298.7 \times 4.5=1344 \mathrm{kN}$.

6. The circular column is then designed using ACI318-95 for axial load due to superstructure weight of $7517 \mathrm{kN}$ plus column self weight of $375 \mathrm{kN}$ and the bending moment due to lateral force $=f_{y}: M=h f_{y}=12096 \mathrm{kN}-\mathrm{m}$. For the resulting column design, $\rho_{t}=3.62 \%$, flexural strength $=12976 \mathrm{kN}-\mathrm{m}$, and lateral strength $=1441 \mathrm{kN}$. For $\rho_{t}=3.62 \%$, $E I=4.24 \times 10^{6} \mathrm{kN}-\mathrm{m}^{2}, k=174.4 \mathrm{kN} / \mathrm{cm}$, and $u_{y}=f_{y} / k=1441 / 174.4=8.27 \mathrm{~cm}$.

7. Since the yield deformation computed in Step 6 differs significantly from the initial estimate of $u_{y}=4.5 \mathrm{~cm}$, iterations are necessary.

The procedure converged after five iterations giving a column design with $\rho_{t}=5.5 \%$. This column has an initial stiffness, $k=238.6 \mathrm{kN} / \mathrm{cm}$ and lateral yield strength, $f_{y}=1907 \mathrm{kN}$. The deformation demand $u_{m}=26.0 \mathrm{~cm}$. Due to reason of brevity, results of intermediate iterations are not presented here; they are available in Chopra and Goel (2000).

\section{Evaluation of Example Designs}

The column design resulting from both procedures is evaluated in this section. Whether a design is satisfactory will be judged by calculating the deformation demand and plastic rotation demand imposed by the design earthquake. These demands can be computed for a system with known properties (initial elastic stiffness, $k$, mass, $m$, and yield-strength $f_{y}$ ) by the following procedure: 
1. Calculate the initial elastic period, $T_{n}$, from the known mass, $m$, and the initial elastic stiffness, $k$.

2. Determine the pseudo-acceleration $A$ from the elastic design spectrum; the elastic design force, $f_{o}=(A / g) w$.

3. Calculate the yield-strength reduction factor, $R_{y}=f_{o} / f_{y}$, in which $f_{o}$ is computed in Step 2 and $f_{y}$ is known yield-strength of the designed system.

4. Determine the ductility demand $\mu$ using the $R_{y}-\mu-T_{n}$ relations.

5. Calculate $u_{m}$ from Equation 9, and $\theta_{p}$ from Equation 6, where $u_{y}=f_{y} / k$ and $f_{y}$ is known yield-strength of the system.

The deformation and plastic rotation demands are computed by this procedure for the example system and compared with those estimated by the two afore-mentioned design procedures.

Structural Design Using Elastic Design Spectra. In designing the structure by using the elastic design spectra for equivalent linear systems, the deformation of the designed structure was estimated to be $26.8 \mathrm{~cm}$. However, when the designed structure is analyzed, the deformation demand is $39.7 \mathrm{~cm}$. Which of the two values is more accurate? Clearly it is the latter value because it comes from inelastic design spectra which are based on nonlinear response history analyses of inelastic systems considering a wide range of system parameters and many ground motions (Krawinkler and Nassar, 1992; Vidic, Fajfar, and Fischinger, 1994). In contrast, the former value comes from an approximate procedure based on equivalent linear systems, a procedure that is known to be inaccurate (Chopra and Goel, 2000). Thus the design procedure has underestimated the deformation demand by $32.6 \%$.

The displacement-based design procedure based on elastic design spectra for equivalent linear systems has additional deficiencies. Although the structure was designed for an acceptable value of the plastic rotation $\theta_{p}=0.02$ radians, the plastic rotation demand $=0.0343$ radians, $72 \%$ more than the acceptable value. Thus the design procedure leaves an erroneous impression that the allowable plastic rotation constraint has been satisfied.

Structural Design Using Inelastic Design Spectra. In designing the structure by the procedure based on inelastic design spectra, the deformation demand for the designed structure was estimated to be $26.0 \mathrm{~cm}$. When the designed structure is analyzed, the deformation demand is $25.9 \mathrm{~cm}$. Clearly the design procedure has estimated the deformation demand consistent with that predicted by well-established concepts of inelastic design spectra. Furthermore, the plastic rotation demand of 0.0199 radians is essentially identical to the acceptable value of 0.02 radians that was imposed on the design, and the proposed procedure has produced a satisfactory design.

Note that for the examples considered, the displacement-based design procedure using inelastic design spectra leads to a structure with more longitudinal reinforcement and thus higher strength compared to the design based on elastic design spectra for equivalent linear systems. A stronger column is necessary to satisfy the selected design criteria. 


\section{Conclusions}

Direct displacement-based design requires a simplified procedure to estimate the seismic deformation of an inelastic SDF system, representing the first (elastic) mode of vibration of the structure, an MDF system. A simplified procedure that uses the well-known inelastic design spectra has been presented in this paper. With the aid of examples, it has been demonstrated that the procedure (1) provides displacement estimates consistent with those predicted by the wellestablished concepts of inelastic design spectra, and (2) produces a structural design that satisfies the design criteria for acceptable plastic rotation.

The displacement-based design procedure proposed by several researchers in recent years uses elastic design spectra for equivalent linear systems based on the secant stiffness method or its variations like the substitute structure method. In this paper, it is demonstrated that the deformation and ductility factor that are estimated in designing the structure by this procedure are much smaller than the deformation and ductility demands determined by nonlinear analysis of the system using inelastic design spectra. Furthermore, it has been shown that the plastic rotation demand on structures designed by this procedure may exceed the acceptable value of the plastic rotation. Thus, the design procedure leaves an erroneous impression that the allowable plastic rotation constraint has been satisfied.

\section{Acknowledgments}

This research investigation is supported by the National Science Foundation under Grant CMS9812531. The authors are grateful for this support.

\section{References}

Chopra, A. K. (1995). Dynamics of structures: Theory and applications to earthquake engineering. Prentice Hall, Upper Saddle River, NJ.

Chopra, A. K. and Goel, R. K. (2000). "Direct displacement-based design: use of inelastic design spectra versus elastic design spectra". Accepted for Publication, Earthquake Spectra.

Chopra, A. K. and Goel, R. K. (2000). "Evaluation of a NSP to estimate seismic deformation: SDF systems." Journal of Structural Engineering, ASCE, Vol. 126, No. 4, pp. 482-490.

Chopra, A. K. and Goel, R. K. (1999). "Capacity-demand-diagram methods for estimating seismic deformation of inelastic structures: SDF systems." Report No. PEER-1999/02, Pacific Earthquake Engineering Research Center, University of California, Berkeley, April.

Jennings, P. C. (1968). "Equivalent viscous damping for yielding structures." Journal of the Engineering Mechanics Division, ASCE, Vol. 94, No. EM1, pp. 103-116.

Kowalsky, M., Priestley, M. J. N., and MacRae, G. A. (1994). "Displacement-based design of RC bridge columns." Proceedings, $2^{\text {nd }}$ International Workshop on the Seismic Design of Bridges, Queenstown, New Zealand, Vol. 1, pp. 138-163.

Krawinkler, H., and Nassar, A. A. (1992). "Seismic design based on ductility and cumulative damage demands and capacities." Nonlinear Seismic Analysis and Design of Reinforced Concrete Buildings, P. Fajfar and H. Krawinkler, Eds., Elsevier Applied Science, New York, 1992. 
Miranda, E., and Bertero, V. V. (1994). "Evaluation of strength reduction factors for earthquakeresistant design." Earthquake Spectra, Vol. 10, No. 2, pp. 357-379.

Moehle, J. P. (1992). "Displacement-based design of R/C structures subjected to earthquakes." Earthquake Spectra, Vol. 8, No. 3, pp. 403-427.

Newmark, N. M., and Hall, W. J. (1982). Earthquake Spectra and Design. Earthquake Engineering Research Institute, Berkeley, CA.

Preistley, M. J. N., Seible, F., and Calvi, G. M. (1996). Seismic design and retrofit of bridges. John Wiley \& Sons, New York, NY.

Priestley, M. J. N., and Calvi, G. M.. (1997). "Concepts and procedures for direct displacementbased design." Seismic Design Methodologies for the Next Generation of Codes, Fajfar and Krawinkler (eds), Balkema, Rotterdam, pp. 171-181.

Shibata, A., and Sozen, M. A. (1976). "Substitute structure method for seismic design in R/C." Journal of the Structural Division, ASCE, Vol. 102, No. ST1, pp. 1-18.

Vidic, T., Fajfar, P., and Fischinger, M. (1994). "Consistent inelastic design spectra: strength and displacement.” Earthquake Engineering and Structural Dynamics, Vol. 23, No. 5, pp. 507-521. 